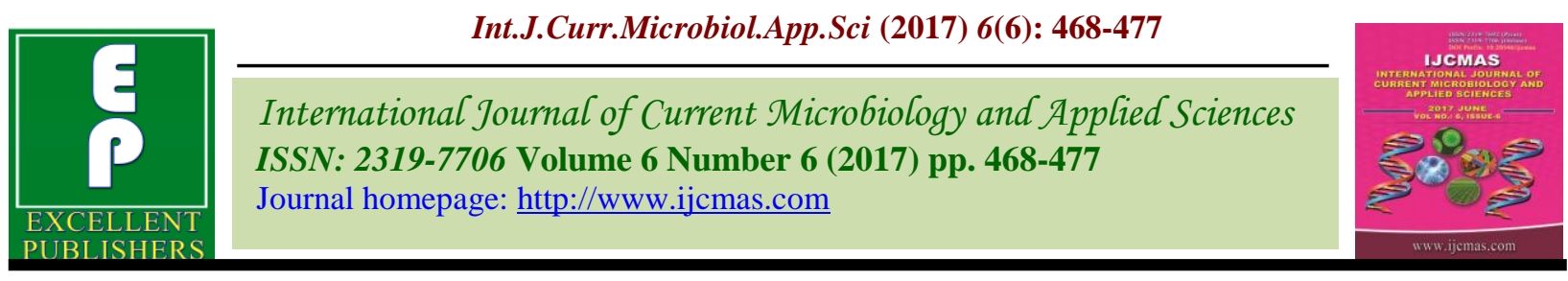

Original Research Article

https://doi.org/10.20546/ijcmas.2017.606.054

\title{
Foliar Endophytic Diversity of Centella asiatica (L.) Urban in Relation to Different Seasons and Leaf Age
}

\author{
Shubhpriya Gupta and Preeti Chaturvedi* \\ Department of Biological Sciences, College of Basic Sciences and Humanities, \\ Pantnagar-263145, India \\ *Corresponding author
}

\section{A B S T R A C T}

\begin{tabular}{|l|}
\hline Ke y w o r d s \\
Endophytic fungi, \\
Centella asiatica, \\
Season, \\
Colonization \\
frequency, \\
Sterilization \\
\hline Article Info \\
\hline Accepted: \\
05 May 2017 \\
Available Online: \\
10 June 2017 \\
\hline \hline
\end{tabular}

Fungal endophytes are a rich source of bioactive metabolites profoundly influencing plant health and ecology. Endofungal diversity depends heavily on the biotic characters of the host and its abiotic growth conditions. To assess and bioprospect endofungal diversity in plants, it is essential to understand these factors. In the present study, isolation and assessment of colonization frequency of endophytic fungi was studied in young and mature leaves of an important medicinal herb viz., Centella asiatica L. Urban in summer, rainy and winter seasons. A maximum of 13 isolates were found during rainy season, 10 in summer and 7 in winter season with colonization frequency of $38.37 \%, 26.37 \%$ and $15.40 \%$ respectively. The Shannon-Wiener Diversity Index of endophytic fungi was highest in rainy season (2.24) and lowest in winter season (1.7). Likewise, the colonization frequency of endophytic fungi isolated from mature leaf was highest $(47.02 \%)$ followed by young leaf $(29.72 \%)$ in rainy season signifying the probable effects of leaf age on the diversity and distribution of endophytes. Results indicate that Colletotrichum gloeosporioides was the dominant species during all the seasons with mean colonization frequency of $24.56 \%$.

\section{Introduction}

Endophytic fungi reside in an asymptomatic manner in apoplastic spaces and/or within the living cells of the plants for at least a significant part of their life cycles (Petrini, 1991). Endophytic fungi produce bioactive natural compounds, many of which are potentially useful in medicine, agriculture and industry (Strobel, 2003). Interestingly, there are several examples of medicinal plants that inhabit endophytes capable of producing host metabolites (Kusari and Spiteller, 2013). The metabolites from endophytic fungi have an edge over host metabolites. These can be acquired at a superior level and can be mass multiplicated in bioreactors, and hence, are more economical to produce. Centella asiatica (L.) Urban (Apiaceae), also known as Gotu kola or Indian pennywort, is a small, annual, slender, creeping entwined herb that grows near swamps on damp ground. In Himalayan region, it occurs up to an altitude of $700 \mathrm{~m}$ (Bagchi and Puri, 1988). This ethnomedicinal species is extensively used for wound healing, memory enhancement, immunomodulatory and antidepressant activity (Joshi and Chaturvedi, 2013). The plant has also been used in folk medicines for several hundred years. The leaves of $C$. 
asiatica form economically most important part of the plant and are known to harbor endophytes (Nath et al., 2014). To ensure successful isolation of endophytic fungi from the host plant, it is important to know the effect of various intrinsic and extrinsic factors. Needless to say, ecology of fungal endophytes is influenced greatly by these factors (Ruscoe, 1971; Hata et al., 1998; Breeze and Dix, 1981; Sahashi et al., 1999). Following effective isolation procedure is thus, very imperative to get maximum endofungal diversity. Therefore, in the present study Centella asiatica, an immensely valuable medicinal herb was explored for its endophytic diversity in relation to age of the leaf and season of isolation.

\section{Materials and Methods}

\section{Collection of plant material}

The healthy and mature plants of $C$. asiatica (Apiaceae) were obtained from Pantnagar (latitude N 28.9700 ${ }^{\circ}$, longitude E $79.4100^{\circ}$ ) for the investigation of endophytic fungal communities. The plant samples were identified, authenticated, and presently maintained at the respective collection center. Collection of leaves was done in summer, rainy and winter seasons. The harvested samples were young and mature photosynthetic leaves randomly chosen from different parts of the plants of the same age group present in the same vicinity. The leaves were ensured to be free from any incision. Plucked leaves were immediately sealed with the autoclaved paraffin wax to reduce the risk of contamination from the cut surface. The samples were brought to the laboratory in sterile bags and processed immediately.

\section{Sterilization and isolation of foliar endophytic fungi}

Sterilization of the plant tissue for endophyte isolation is the most important step. Lack of proper sterilization leads to contamination of the material which could be mistaken as endophytic fungi. This eventually reduces the efficacy of the experiment and will mislead the results. Therefore, sterilization of the leaf explants was standardized to eliminate contamination. For effective surface sterilization of leaf tissue, various treatments were analyzed (Table 1). Surface-sterilization of the explants was done following the previously established methods with slight modifications (Lodge et al., 1996, Puri et al., 2005). Leaf explants of $C$. asiatica were washed under running tap water followed by washing with Tween 20 (3-4 drops), dipped in $0.1 \%$ Bavistin $(20 \mathrm{~min}$.) with constant agitation and then rinsed 4-5 times with sterile water. It was further surface sterilized using $70 \%$ ethanol for 30 seconds, followed by dipping in $2 \%$ sodium hypochloride for a minutes. This was again treated with $70 \%$ ethanol for 30 seconds. and washed with sterile water 3-4 times (Table 1). Finally, the sterilized leaf segments were cut with surgical blade and placed in PDA medium amended with $50 \mathrm{mg} / \mathrm{L}$ streptomycin. Petri dishes were sealed using Parafilm and incubated at $28 \pm$ $2^{\circ} \mathrm{C}$ in an incubator (REMI).

The cultures were monitored every day to check the growth of endophytic fungal colonies from the leaf segments. The hyphal tips, which grew out from leaf segments over 1-2 weeks were then isolated and subcultured on a PDA medium. The effectiveness of surface-sterilization is checked by taking surface prints of the sterilized leaves, non sterilized leaves and by spreading dist. water in which sterilized leaf was washed last on the PDA medium.

\section{Identification of foliar endophytic fungi}

The morphological analysis of isolated strains was done using a compound microscope. Slides were prepared in lactophenol cotton blue for observation of spores and other 
characteristics. Identification of the fungi was made following Barnett and Hunter (1998).

\section{Isolation and colonization frequency (\%)}

The Isolation frequency (IF) of a single endophytic fungal species was calculated as follows (Hata et al., 2002):

Isolation frequency $=$

Total number of segments from which fungus was isolated $\times 100$

Total number of segments analyzed

Colonization frequency or endophytic infection rate was calculated as follows (Suryanarayanan et al., 2003):

Colonization frequency $=$

Total number of segments colonized by fungi

Total number of segments analyzed

\section{Shannon- Wiener diversity Index (H')}

The Shannon Wiener diversity index $\left(\mathrm{H}^{\prime}\right)$ for colonization of fungal isolates was calculated by the formula:

$H^{\prime}=-\Sigma[(p i \times \ln (p i)]$

Where, pi $=$ Number of individual species $\mathrm{i} /$ total number of samples

The diversity analyses were performed by using the MS Excel program.

\section{Results and Discussion}

\section{Isolation and identification of endophytic} fungi

Out of the different sterilization procedures used, treatment no. 6 was the best one for sterilization of leaf explants (Table 1). A total of 13 endophytic isolates were isolated from C. asiatica viz. CaEF1: C. gloeosporioides; CaEF2: Colletotrichum sp.; CaEF3: Fusarium sp.; CaEF4: Curvularia sp.; CaEF5: Nigrospora sp.; CaEF6: Alternaria sp.; CaEF7: Aspergillus sp.; Fusarium equiseti; CaEF9; CaEF10; CaEF11; CaEF12; CaEF13 (Figs. 1 and 2). Most of the fungal endophytes of $C$. asiatica were morphologically identified (Courtesy: Dr. A.K Tewari, G.P.B.U.A.T, Pantnagar). All the endophytes belonged to the division ascomycota in conformity with the results of Xiong et al., (2013) and Anitha et al., (2013). Ascomycota is the largest phylum of Fungi (Kirk et al., 2008). The significant feature of this fungal group is the ascus, a microscopic sexual structure in which non motile spores, called ascospores are formed. However, some species of the ascomycota are asexual, means that they do not have a sexual cycle and thus do not form asci or ascospores. In the present study, five endophytic fungal isolates viz., CaEF9, CaEF10, CaEF11, CaEF12, CaEF13 were found to be sterile mycelia and did not produce spores and were not identified. Several workers have reported endophytes that do not sporulate under cultivation, and are therefore classified as sterile fungi (Suryanarayanan et al., 1998; Kumaresan and Suryanarayanan, 2001; Ananda and Sridhar, 2002). Thus, in the present study, a total of 8 endophytic fungi viz. Colletotrichum gloeosporioides, Colletotrichum sp., Fusarium sp., Curvularia sp., Nigrospora sp., Alternaria sp., Aspergillus sp. and F. equiseti were identified and characterized further, as these isolates were present during isolation in all the three seasons.

Colonization and isolation frequency of endophytic fungi isolated from $C$. asiatica

Three hundred and seventy segments of young and mature leaves of $C$. asiatica were screened over the three season's viz. summer, 
rainy and winter, representing a mean colonization frequency of $26.37 \%, 38.37 \%$ and $15.40 \%$ respectively. The colonization rate was $16.75 \pm 1.9 \%, 29.72 \pm 1.42 \%$ and $11.35 \pm 1.11 \%$ in young leaf and $36.0 \pm 1.05 \%$, $47.02 \pm 1.12 \%$ and $19.45 \pm 1.41 \%$ in mature leaf during summer, rainy and winter seasons respectively (Table 2).

The higher colonization in mature leaf as compared to young leaf over all the three seasons suggests that mature leaf provides more favourable environment for the establishment of endophytic fungi. The results of the present study perfectly coincides with the previous studies (Suryanarayanan and Thennarasan, 2004; Fernandez et al., 2001; Hilarino et al., 2011).

Endophytes are known to accumulate as tissue ages (Arnold and Lutzoni, 2007; Kumaresan and Suryanarayanan, 2002). Nascimento et al., (2015) also reported that the rate of endophyte colonization increased with the leaf age/development and reported $32.1 \%$ colonization rate of endophytic fungi in leaves of Calotropis procera. Similarly, the leaves of Coscinium fenestratum of different maturity showed different rates of colonization (Goveas et al., 2011). Others have also found that endophytes colonization varied with season and/or leaf age (Cabral, 1985; Osono and Mori, 2005). The low rate of colonization in younger leaves could be due to their chemically different nature from mature leaves. These have higher concentration of antifungal and anti-herbivore substances (Coley and Barone, 1996). Moreover, longer duration of tissue exposure to the environment could also lead to an increase in the number of endophytic fungal isolates (Arnold and Herre, 2003).

In the present study, the colonization percentage of endophytic fungi was found to be maximum in rainy season $(38.37 \%)$ and minimum in winter $(15.40 \%)$. The result is in conformity with Tejesvi et al., (2005) who also reported greater endophytic fungal diversity during monsoon season in twigs and bark of Terminalia arjuna. Whereas, Naik et al., (2007) reported that the number of isolates from leaf segments of 15 medicinal shrubs, obtained during the winter season were significantly more than in monsoon and summer seasons.

The Shannon-Wiener Diversity Index of endophytic fungi isolated in summer, rainy and winter season was found to be 2.02, 2.24 and 1.7 respectively demonstrating that rainy season has a more diverse fungal community compared to summer and winter seasons. Contrary to this, Fang et al., (2013) found that the Shannon-Wiener indices for endophytic fungi isolated from Camellia sinensis in spring are higher than in winter and autumn.

The difference in seasonal pattern can be partly related to the seasonal behavior of major endophytes. Spring is mostly the active season of infection. During this period, a large number of fungal species colonize in plant. Nevertheless, the activity of secondary metabolites is different throughout the year, which is also an important factor affecting seasonal variation in endophytes. The low diversity indices of endophytes may also be associated with the presence of a few dominant species of endophytic fungi.

The isolation frequency of each endophytic fungus in summer, rainy and winter seasons is shown in table 3. The isolation frequency of C. gloeosporioides was $24.59 \pm 1.20$, $28.37 \pm 0.76$ and $19.45 \pm 1.62$ and that of Fusarium sp. was $12.16 \pm 0.42,21.89 \pm 1.55$ and $16.48 \pm 1.53$ in summer rainy and winter seasons 
Table.1 Treatments for effective sterilization of leaf explant

\begin{tabular}{|l|l|l|}
\hline S. No. & \multicolumn{1}{|c|}{ Treatment } & Contamination level \\
\hline 1 & $2 \% \mathrm{NaOCl}+70 \%$ ethanol $(1 \mathrm{~min})$. & $\begin{array}{l}\text { High bacterial and } \\
\text { fungal contamination }\end{array}$ \\
\hline 2 & Tween $20+70 \%$ ethanol $(30 \mathrm{sec})+2 \% \mathrm{NaOCl}(30 \mathrm{sec})$ & $\begin{array}{l}\text { High bacterial and } \\
\text { fungal contamination }\end{array}$ \\
\hline 3 & $\begin{array}{l}\text { Tween } 20+70 \% \text { ethanol }(30 \mathrm{sec})+2 \% \mathrm{NaOCl}(30 \mathrm{sec})+70 \% \\
\text { ethanol }(30 \mathrm{sec})\end{array}$ & $\begin{array}{l}\text { Moderate bacterial and } \\
\text { fungal contamination }\end{array}$ \\
\hline 4 & $\begin{array}{l}\text { Tween } 20+70 \% \text { ethanol }(30 \mathrm{sec})+2 \% \mathrm{NaOCl}(30 \mathrm{sec})+70 \% \\
\text { ethanol }(30 \mathrm{sec})+\text { Streptomycin }(50 \mathrm{mg} / \mathrm{L}) \text { amended in media }\end{array}$ & $\begin{array}{l}\text { Moderate fungal } \\
\text { contamination }\end{array}$ \\
\hline 5 & $\begin{array}{l}\text { Tween } 20+0.1 \% \text { Bavistin }(10 \mathrm{~min})+70 \% \text { ethanol }(30 \mathrm{sec})+2 \% \\
\text { NaOCl }(1 \mathrm{~min})+70 \% \text { ethanol }(30 \mathrm{sec})+\mathrm{Streptomycin}(50 \mathrm{mg} / \mathrm{L}) \\
\text { amended in media }\end{array}$ & $\begin{array}{l}\text { Low fungal } \\
\text { Contamination }\end{array}$ \\
\hline 6 & $\begin{array}{l}\text { Tween } 20+0.1 \% \text { Bavistin }(20 \mathrm{~min})+70 \% \text { ethanol }(1 \mathrm{~min})+2 \% \\
\text { NaOCl }(1 \mathrm{~min})+70 \% \text { ethanol }(30 \mathrm{sec})+\text { Streptomycin }(50 \mathrm{mg} / \mathrm{L}) \\
\text { amended in media }\end{array}$ & No Contamination \\
\hline
\end{tabular}

Table.2 Colonization frequency (\%) of endophytic fungi from young and mature leaves of C. asiatica in different seasons

\begin{tabular}{|c|c|c|c|c|c|c|}
\hline \multirow{2}{*}{} & \multicolumn{4}{|c|}{ Seasons } \\
\cline { 2 - 7 } & \multicolumn{2}{|c|}{ Summer } & \multicolumn{2}{|c|}{ Rainy } & \multicolumn{2}{c|}{ Winter } \\
\cline { 2 - 6 } & Young leaf & Mature leaf & Young leaf & Mature leaf & Young leaf & Mature leaf \\
\hline $\begin{array}{c}\text { Colonization } \\
\text { Frequency (CF) } \\
(\%) \pm \text { SE }\end{array}$ & $16.75 \pm 1.9$ & $36.0 \pm 1.05$ & $29.72 \pm 1.42$ & $47.02 \pm 1.12$ & $11.35 \pm 1.11$ & $19.45 \pm 1.41$ \\
\hline $\begin{array}{c}\text { Mean CF (\%) } \\
\text { over three } \\
\text { seasons }\end{array}$ & \multicolumn{2}{|c|}{26.37} & \multicolumn{2}{|c|}{38.37} & \multicolumn{2}{|c|}{15.40} \\
\hline & CD at $1 \%$ & \multicolumn{2}{|c|}{ CD at 5\% } & \multicolumn{2}{|c|}{ SEm } \\
\hline Leaf (L) & 3.41 & \multicolumn{2}{|c|}{2.43} & \multicolumn{2}{c|}{0.79} \\
\hline Season (S) & 4.18 & \multicolumn{2}{|c|}{2.98} & 0.96 \\
\hline Interaction (L×S) & 5.91 & 4.21 & 1.36 \\
\hline
\end{tabular}


Table.3 Isolation frequency of foliar endophytic fungi isolated from C. asiatica in summer, rainy and winter seasons

\begin{tabular}{|c|c|c|c|c|c|}
\hline \multirow[t]{2}{*}{ S.No. } & \multirow[t]{2}{*}{$\begin{array}{c}\text { Foliar Endophytic } \\
\text { Fungal Isolates }\end{array}$} & \multicolumn{4}{|c|}{ Isolation frequency of endophytic fungi (\%) } \\
\hline & & Summer & Rainy & Winter & Mean (\%) \\
\hline 1 & $\begin{array}{l}\text { Colletotrichum } \\
\text { gloeosporioides }\end{array}$ & $24.59 \pm 1.20$ & $28.37 \pm 0.76$ & $19.45 \pm 1.62$ & 24.14 \\
\hline 2 & Colletotrichum sp. & $9.7 \pm 0.56$ & $11.35 \pm 0.94$ & - & 10.54 \\
\hline 3 & Fusarium sp. & $12.16 \pm 0.42$ & $21.89 \pm 1.55$ & $16.48 \pm 1.53$ & 16.84 \\
\hline 4 & Curvularia sp. & $15.4 \pm 1.12$ & $18.91 \pm 1.42$ & $12.97 \pm 1.36$ & 15.7 \\
\hline 5 & Nigrospora sp. & $3.78 \pm 0.56$ & $5.67 \pm 1.15$ & $2.43 \pm 0.61$ & 3.96 \\
\hline 6 & Alternaria sp. & $14.05 \pm 1.14$ & $10.27 \pm 1.42$ & $11.62 \pm 1.68$ & 11.98 \\
\hline 7 & Aspergillus sp. & $10.81 \pm 1.49$ & $18.64 \pm 1.46$ & $15.13 \pm 1.47$ & 14.86 \\
\hline 8 & Fusarium equiseti & $6.4 \pm 0.82$ & $3.2 \pm 0.61$ & $4.32 \pm 1.09$ & 4.68 \\
\hline 9 & CaEF9 & - & $3.51 \pm 0.59$ & - & 3.51 \\
\hline 10 & CaEF10 & - & $1.89 \pm 0.40$ & - & 1.89 \\
\hline 11 & CaFE11 & $1.08 \pm 0.10$ & $5.13 \pm 0.61$ & - & 3.1 \\
\hline 12 & CaEF12 & - & $1.35 \pm 0.39$ & - & 1.35 \\
\hline 13 & CaEF13 & $0.5 \pm 0.57$ & $4.86 \pm 0.75$ & - & 2.70 \\
\hline & & \multicolumn{2}{|c|}{$\mathrm{CD}$ at $5 \%$} & \multicolumn{2}{|c|}{ SEm } \\
\hline & Season $(\mathrm{S})$ & \multicolumn{2}{|c|}{0.73} & \multicolumn{2}{|c|}{0.26} \\
\hline & Endophytic Fungi (EF) & \multicolumn{2}{|c|}{1.53} & \multicolumn{2}{|c|}{0.54} \\
\hline & Interaction $(\mathrm{S} \times \mathrm{EF})$ & \multicolumn{2}{|c|}{2.65} & \multicolumn{2}{|c|}{0.94} \\
\hline
\end{tabular}


Fig.1 Endophytic fungi emerging from leaf explants of $C$. asiatica

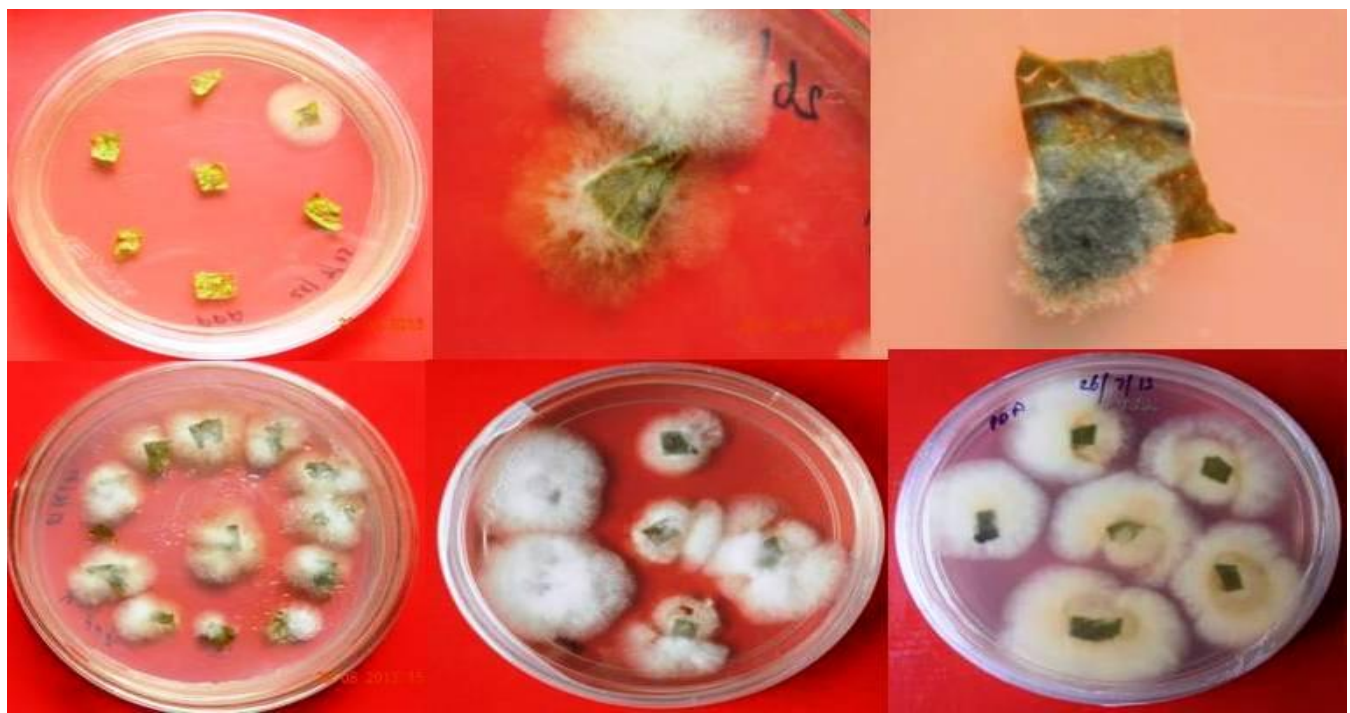

Fig.2 Morphological characteristics of foliar endophytic fungi from $C$. asiatica (a) $C$. gloeosporioides (b) Colletotrichum sp. (c) Fusarium sp. (d) Curvularia sp. (e) Nigrospora sp. (f) Alternaria sp. (g) Aspergillus sp. (h) F. equiseti (i) CaEF9 (j) CaEF10

(k) CaEF11 (1) CaEF12 (m) CaEF13

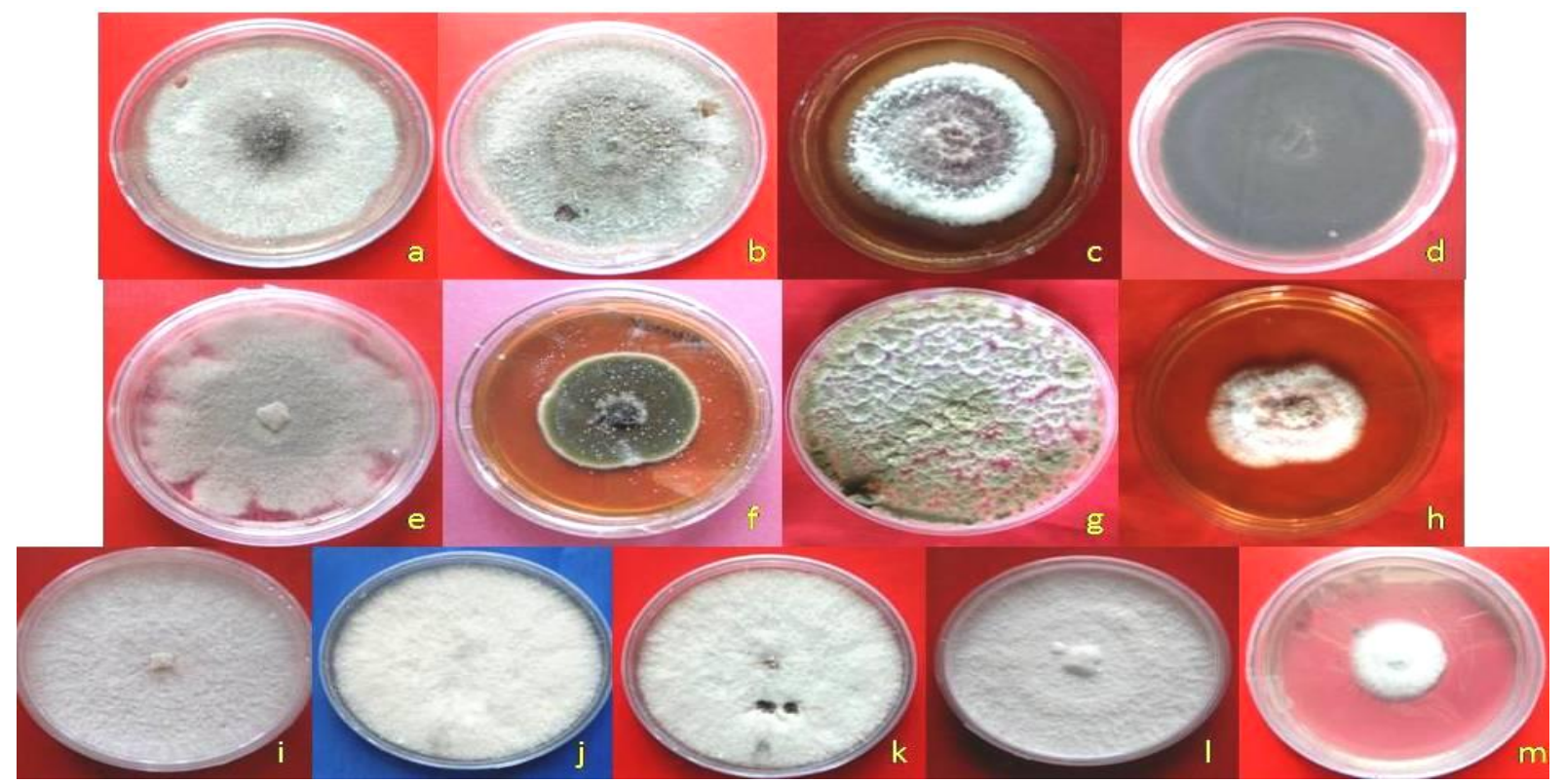

C. gloeosporioides was the most dominant fungus with mean isolation frequency of $24.14 \%$ followed by Fusarium sp. (16.84\%). $C$. gloeosporioides was also reported to be the predominant endophyte of Jatropha curcas (Kumar and Kaushik, 2013). Nascimento et al., (2015) reported Phaeoramularia calotropidis
(63.5\%) as dominant endophyte in Calotropis procera leaves.

The dominance of one or a few species is commonly reported in other isolation studies of endophytic fungi (Suryanarayanan et al., 2003 Huang et al., 2008). The high frequency of 
isolation of these endophytic fungi compared to others might be due to spore abundance in the plant tissue (Verma et al., 2013). The sterile mycelia CaEF9, CaEF10, CaEF11, CaEF12, and $\mathrm{CaEF} 13$ were present in rainy season, CaEF11 and CaEF13 in summer season while none were present in winter season. The lowest mean isolation frequency of $1.35 \%$ was found in sterile mycelia isolate CaEF12. Hata et al., (2002) reported month wise colonization frequency of endophytic fungal isolates from the leaves of Pasania edulis and found 11 fungal isolates which were sterile mycelia. In a survey of endophytic fungi from fronds of Livistona chinensis, $16.5 \%$ of total isolates did not sporulate, and were assigned as mycelia sterilia (Guo et al., 2000). From the study, it is apparent that the endophytic community of a plant is dependent on plethora of factors viz., the exposure time, size of contact surface, nutrient composition, environmental factors, the number of cuts and wounds and/or natural openings (for e.g. stomata) in the plant tissue or interaction between endophytes themselves that may operate individually or synergistically.

In conclusion, endophytic organisms have received considerable attention only recently after they were found to protect their host against insect pests, pathogens and herbivores. Most of the studies on endophytes are limited to biodiversity, taxonomy, reproduction, host ecology and their influence on host. An upcoming area of study on endophytes is their ability to produce bioactive metabolites of endophytic/host origin. To efficiently carry out such study, it is pertinent to understand the influence of important factors that govern the isolation frequency of these organisms. The results of the present study on foliar endophytic fungi of $C$. asiatica revealed season and age related influence on endophytic fungal population of the plant. This clearly indicated that the colonization of endophytic fungi depends on both environmental conditions and intrinsic factors i.e. bioactive composition of host plant which itself is influenced by plant age. This is definitely an essential information required for optimizing the effective isolation of endophytes as well as efficient production of the important metabolites. Further research about the mutual influence of $C$. asiatica and the foliar endophytic fungal diversity is essential in the future study.

\section{Acknowledgements}

First author is highly thankful to DES, Govind Ballabh Pant University of Agriculture and Technology, Pantnagar, for funding the project. The authors are also thankful to Dr. A.K Tewari, Professor, Department of Plant Pathology, College of Agriculture and Dr. A.K Sharma, Professor, Department of Biological Sciences College of Basic Sciences and Humanities, G.B.P.U.A. and T, Pantnagar for providing the necessary help to carry out this research work.

\section{References}

Ananda, K. and Sridhar, K.R. 2002. Diversity of endophytic fungi in the roots of mangrove species on west coast of India. Can J Microbiol, 48: 871-878.

Anitha, D., Vijaya, T., Pragathi, D., Reddy, N.V., Mouli, K.C., Venkateswarulu, N. and Bhargav, D.S. 2013. Isolation and characterization of endophytic fungi from endemic medicinal plants of Tirumala hills, Int J Life Sci Biotechno Pharma Res, 2: 3.

Arnold, A.E. and Herre, E.A.2003. Canopy cover and leaf age affect colonization by tropical fungal endophytes: Ecological pattern and process in Theobroma cacao (Malvaceae). Mycologia 95(3): 388398.

Arnold, A.E. and Lutzoni, F.2007. Diversity and host range of foliar fungal endophytes: are tropical leaves biodiversity hotspots? Ecology 88: 541549.

Bagchi, G.D. and Puri, H.S.1988. Centella asiatica. Herb Hung 27 (2-3): 137-140.

Barnett, H.L. and Hunter, B.B.1998. Illustrated Genera of Imperfect Fungi. APS Press, Minnesota, USA. 
Breeze, E.M. and Dix, N.J.1981. Seasonal analysis of the fungal community on Acer platanoides leaves. T Brit Mycol Soc 77:321-328.

Cabral, D.1985. Phyllosphere of Eucalyptus viminalis: dynamics of fungal populations. T Brit Mycol Soc.85:501511.

Coley, P.D. and Barone, J.A.1996. Herbivory and plant defenses in tropical forests. Annu Rev Ecol Syst 27: 305-335.

Fang, W., Yang, L., Zhu, X., Zeng, L. and Li, X.2013. Seasonal and habitat dependent variations in culturable endophytes of Camellia sinensis, J Plant Pathol Microbiol 4:3.

Fernandes, G.W., Oki, Y., Sanchez-Azofeifa, A., Faccion, G. and Amaro-Arruda, H.C. 2011. Hail impact on leaves and endophytes of the endemic threatened Coccoloba cereifera (Polygonaceae). Plant Ecol. 212: 1687-1697.

Goveas, S.W., Madtha, R., Nivas, S.K. and D'Souza, L.2011. Isolation of endophytic fungi from Coscinium fenestratum -a red listed endangered medicinal plant, Eurasia J Biosci. 5: 4853.

Guo, L.D., Hyde, K.D. and Liew, E.C.Y.2000. Identification of endophytic fungi from Livistona chinensis (Palmae) using morphological and molecular techniques. New Phytol 147: 617-630.

Hata, K., Atari, R. and Sone K.2002. Isolation of endophytic fungi from leaves of Pasania edulis and their within-leaf distributions. Mycoscience 43: 369373.

Hata, K., Tsuda, M. and Futai, K.1998. Seasonal and needle age-dependent changes of the endophytic mycobiota in Pinus thunbergii and Pinus densiflora needles. Can J Bot, 76:245-250.

Hilarino, M.P.A., Silveira, F.A.O., Oki, Y., Rodrigues, L., Santos, J.C., CorreaJunior, A., Fernandes, G.W. and Rosa, C.A. 2011. Distribution of the endophytic fungi community in leaves of Bauhinia brevipes (Fabaceae). Acta Bot Bras25: 815-821.

Huang, W.Y., Cai, Y.Z., Hyde, K.D., Corke, H. and Sun, M.2008. Biodiversity of endophytic fungi associated with 29 traditional Chinese medicinal plants. Fungal Diversity, 33: 61-75.

Joshi, K and Chaturvedi, P. 2013. Therapeutic efficiency of Centella asiatica L. Urban. An underutilized green leafy vegetable: an overview. Int $\mathrm{J}$ Pharm Bio Sc 4(1):135-149.

Kirk, P.M., Cannon, P.F., Minter, D.W. and Stalpers, J.A. 2008. Dictionary of the Fungi. 10th ed. Wallingford: CABI. pp 55. ISBN 0-85199-826-7

Kumar, S. and Kaushik, N. 2013. Endophytic fungi isolated from oil-seed crop Jatropha curcas produces oil and exhibit antifungal activity. Plos One 8(2): 56202. doi:10.1371/journal.pone.0056202.

Kumaresan, V. and Suryanarayanan, T.S.2001. Occurrence and distribution of endophytic fungi in a mangrove community. Mycol Res. 105: 13881391.

Kumaresan, V. and Suryanarayanan, T.S.2002. Endophyte assemblages in young mature and senescent of Rhizophora apiculata: evidence for the role of endophytes in mangrove litter degradation. Fungal Divers 9: 81-91.

Kusari, S. and Spiteller, M. 2012. Metabolomics of Endophytic Fungi Producing Associated Plant Secondary Metabolites: Progress, Challenges and Opportunities, Metabolomics, Dr Ute Roessner (Ed.) ISBN: 978-953-510046-1.

Lodge, D.J., Fisher, P.J. and Sutton, B.C.1996. Endophytic fungi of Manilkara bidentata leaves in Puerto Rico. Mycologia 88: 733-738.

Naik, B.S., Shashikala, J. and Krishnamurthy, Y.L.2007. Study on the diversity of endophytic communities from rice (Oryza sativa L.) and their antagonistic 
activities in vitro. Microbiol Res 164: 90-296.

Nascimento, T.L., Oki, Y., Lima, D.M.M., Almeida-Cortez, J.S., Wilson Fernandes, G. and Souza-Motta, C.M. 2015. Biodiversity of endophytic fungi in different leaf ages of Calotropis procera and their antimicrobial activity, Fungal Ecol14: 79-86.

Nath, A., Pathak, J. and Joshi, S.R. 2014. Bioactivity assessment of endophytic fungi associated with Centella asiatica and Murraya koengii. Journal of Applied Biology and Biotechnology. 2(5): 6-11.

Osono, T. and Mori, A.2005. Seasonal and leaf age-dependent changes in occurrence of phyllosphere fungi in giant dogwood. Mycoscience. 46:273-279.

Petrini, O. 1991. Fungal endophytes of tree leaves. In: Andrews JH, Hirano SS (eds), Microbial ecology of leaves. Springer-Verlag, New York, USA pp. 179-197.

Puri, S.C., Verma, V., Amna, T., Qazi, G.N., and Spiteller, M. 2005. An endophytic fungus from Nothapodytes foetida that produces camptothecin. J Nat Prod Plant Res 68: 1717-1719.

Ruscoe, Q.W. 1971. Mycoflora of living and dead leaves of Nothofagus truncata. Trans Br Mycol Soc 56:463-474.

Sahashi, N., Kubono, T., Miyasawa, Y. and Ito, S. 1999. Temporal variations in isolation frequency of endophytic fungi of Japanese beech. Can J Bot 77:197202.

Strobel, G.A.2003. Endophytes as a source of bioactive products. Microb Infect 5(6): 535-534.
Suryanarayanan, T.S. and Thennarasan, S 2004. Temporal variation in endophyte assemblages of Plumeria rubra leaves. Fungal Divers 15: 197-204.

Suryanarayanan, T.S., Kumaresan, V. and Johnson, J.A.1998. Foliar fungal endophytes from two species of the mangrove Rhizophora. Can J Microbiol 44: 1003- 1006.

Suryanarayanan, T.S., Venkatesan, G. and Murali, T.S. 2003. Endophytic fungal communities in leaves of tropical forest trees: diversity and distribution patterns. Current Science 85: 89-493.

Tejesvi, M.V., Mahesh, B., Nalini, M.S., Prakash, H.S., Kini, K.R., Subbiah, V. and Shetty, H.S.2005. Endophytic fungal assemblages from inner bark and twig of Terminalia arjuna $\mathrm{W}$. and A. (Combretaceae). World J Microb and Biot 21: 1535-1540.

Verma, S.K., Gond, S.K., Mishra. A., Sharma, V.K., Kumar, J., Singh, DK., Kumar, A., Goutam, J. and Kharwar, R.N. 2013. Impact of environmental variables on the isolation, diversity and antibacterial activity of endophytic fungal communities from Madhuca indica Gmel. At different locations in India. Ann Microbiol doi: 10.1007/s13213 013-0707-9.

Xiong, Z.Q., Yang, Y.Y., Zhao, N. and Wang, Y.2013. Diversity of endophytic fungi and screening of fungal paclitaxel producer from Anglojap yew, Taxus $x$ media. BMC Microbiol 13:71.

\section{How to cite this article:}

Shubhpriya Gupta and Preeti Chaturvedi. 2017. Foliar Endophytic Diversity of Centella asiatica (L.) Urban in Relation to Different Seasons and Leaf Age. Int.J.Curr.Microbiol.App.Sci. 6(6): 468477. doi: https://doi.org/10.20546/ijcmas.2017.606.054 